Research paper

\title{
Arranged marriages in people with epilepsy: A pilot knowledge, attitudes and practices survey from India
}

\author{
Akriti Gupta ${ }^{\mathrm{a}, *}$, Jasneet Singh Chawla ${ }^{\mathrm{a}}$, Karan Saggar ${ }^{\mathrm{b}}$, Praneet Wander ${ }^{\mathrm{c}}$, \\ Hitant Vohra ${ }^{\mathrm{d}}$, R.K. Bansal ${ }^{\mathrm{e}}$, Caroline Selai ${ }^{\mathrm{f}}$, Gagandeep Singh ${ }^{\mathrm{e}, \mathrm{f}}$ \\ a Dayanand Medical College, Ludhiana, India \\ ${ }^{\mathrm{b}}$ Baba Jaswant Singh Dental College, Ludhiana, India \\ 'Mount Sinai St Luke's Roosevelt Hospital, New York, United States \\ ${ }^{\mathrm{d}}$ Department of Anatomy, Dayanand Medical College, Ludhiana, India \\ e Department of Neurology, Dayanand Medical College, Ludhiana, India \\ ${ }^{\mathrm{f}}$ UCL Institute of Neurology, Queens Square, London WC1N3BG, UK
}

\section{A R T I C L E I N F O}

\section{Article history:}

Received 26 February 2016

Accepted 9 May 2016

Available online 30 July 2016

\section{Keywords:}

Epilepsy

Marriage

Stigma

\begin{abstract}
A B S T R A C T
Introduction: Marriage is a socially challenging barrier in the personal lives of people with epilepsy worldwide. However, it is during arranges marriages, which are common in South Asian communities, that epilepsy is most profoundly stigmatizing. We hypothesized that the felt stigma associated with epilepsy during arranged marriages affects women more frequently and intensely.

Materials and methods: A pilot study in married $(n=38)$ and unmarried PWE $(n=58)$ and general public $(n=150)$ to explore gender-based differences in the stigma associated with epilepsy during arranged marriages.

Results: Majority unmarried PWE (87\%) considered arranged marriage as the best way to realize their matrimonial plans. More unmarried women (72\%) apprehended problems in adhering to their epilepsy medications regime after marriage ( $p$ 0.009) and 50\% apprehended victimization in marriage on account of epilepsy ( $p$ 0.001). Moreover, $41 \%$ of the married women with epilepsy felt that the disclosure had a negative impact on their married life ( $p$ 0.047).

Conclusions: South Asian WWE experienced more felt stigma than men before and after arranged marriages and this might impact a number of health related psychosocial outcomes. The lack of past experience with epilepsy was associated with a number of misplaced beliefs about and attitudes towards epilepsy.
\end{abstract}

(C) 2016 Published by Elsevier, a division of Reed Elsevier India, Pvt. Ltd on behalf of Indian Epilepsy Society.

\section{Introduction}

Epilepsy, one of the commonest neurological disorders, is notable for the stigma associated with it. ${ }^{1-4}$ Stigma denotes an attitude of the society, which discredits an individual because of a specific trait (herein, epilepsy). ${ }^{5,6}$ It impacts a multitude of social spheres including education, employment and marriage in people with epilepsy (PWE). ${ }^{7-9}$ Epilepsy hits hardest during matrimony, often remaining under shadows throughout its course.

\footnotetext{
* Corresponding author at: Department of Neurology, Dayanand Medical College, Ludhiana 141001, Punjab, India. Tel.: +91 9876848844.

E-mail address: aky_gupta@yahoo.in (A. Gupta).
}

Worldwide, matrimonial practices, customs and rituals vary considerably and hence the impact of epilepsy on matrimony must take into account these cross-cultural variations. ${ }^{10} \mathrm{~A}$ peculiar matrimonial practice, known as "arranged marriage", is particularly common in parts of Asia, Africa and Middle-East ${ }^{11}$ (more so in South Asia and South-east Asia). For instance, $89 \%$ of the marriages in India are arranged. ${ }^{12}$ The main feature of arranged marriages is the search for and selection of a prospective spouse by parents and/ or extended family through their social contacts or media using considerations of physical characteristics, socio-economic status, caste and education. The search is often followed by one or more meetings between the families of the prospective partners in which the "marriage is negotiated". Moreover, because the choice of marital partners is with the elders/family, there is limited or often no contact between the partners before marriage. In these 
matrimonial negotiations, physical or mental illnesses are considered discrediting in comparison to high income and education, social status and good looks, which might be pluspoints. Hence, discrediting conditions such as epilepsy are often not disclosed (or willfully concealed) at the time of matrimonial negotiations. On the other hand, disclosure of epilepsy during marital negotiations may result in breakdown of negotiations. A recent consensus meeting of experts identified reduced marital satisfaction, increased chances of divorce, incomplete adherence to epilepsy medications leading to poor seizure control, reduced physician visits and health implications therein as potential consequences of concealing epilepsy during matrimonial negotiations. ${ }^{13}$ The expert group identified a number of gaps in the understanding of interaction between epilepsy and arranged matrimony largely due to the lack of systematically collected population-based data on marital outcome and knowledge, attitudes and practices. Filling up these information gaps was considered crucial to elucidating measures to tackle the problem of arranged marriages in PWE. Finally, the expert group observed that the predicament of arranged marriages in PWE occurs in the backdrop of a deep-rooted gender discrimination (with bias against women) that permeates a number of pursuits including child-rearing, feeding, education, employment, property-rights and matrimony in the prevailing socio-cultural climate in these communities. Because of the gender bias, women might be subject to higher levels of felt and enacted stigma related to epilepsy and perhaps adverse marital outcomes.

We undertook an exploratory pilot survey of knowledge about, attitudes towards, and practices regarding (KAP) matrimony in unmarried and married people with epilepsy (PWE) and the general public. Post hoc, we hypothesized that women experience greater degree of felt stigma associated with epilepsy in arranged marriages and hence, undertook a comparison of the KAP responses by gender.

\section{Material and methods}

We surveyed three groups of people attending hospital: nevermarried PWE $(n=58)$, married PWE $(n=38)$, and lay people without epilepsy or a neurological disorder $(n=150)$. Unmarried and married PWE were above legal minimum marriageable age in India ( $>18$ years for women and $>21$ years for men) and attended the Epilepsy Clinic at a busy secondary-tertiary care pay-for-care hospital in Northwest India. Active epilepsy, identified through a history of seizures in the past five years and ongoing treatment with epilepsy medications with the need of treatment, was confirmed by a neurologist in the study team. Those with concomitant neurologic handicap, intellectual impairment, psychiatric disturbances, or functional non-epileptic events were excluded. Lay people were recruited from those seated in the hospital reception either awaiting consultation in the clinics or those visiting hospitalized patients.

The study design and methods were approved by the institutional ethics committee. Written informed consent was obtained from all subjects. They were then handed questionnaires by volunteers. Questionnaires were carefully designed in English language by neurologists after discussion and consensus and then translated into two regional vernacular languages (Hindi and Punjabi). These forms were purpose-designed for the three groups of subjects with minor differences between the three groups. The questionnaires were similar for all three groups with minor differences. The first five questions assessed knowledge about epilepsy in relation to matrimony, e.g., could epilepsy be a legal ground for divorce? The subsequent four questions gauged attitudes towards epilepsy, for example should people with epilepsy get married? Could they bear children? Were they likely to have sexual problems? The questionnaires were filled up by the subjects themselves, though, volunteers were allowed to offer guidance if required.

The responses obtained from the three groups of subjects were double-entered in to a computerized database and then analyzed using STATA (version 13; StataCorp LP). Descriptive analysis of the responses in the three groups of subjects was performed. In addition, responses were compared between men and women among unmarried and married PWE and between people with and without exposure to epilepsy in the lay subgroup. People who answered in affirmative to any of the three questions: Do you suffer from epilepsy? Do you know someone with epilepsy? Do you have a family member with epilepsy? were categorized as exposed to epilepsy.

Statistical comparisons were performed using the Chi Square test for categorical variables (responses) and the Student's $t$ test for continuous variables (e.g., age). $p$ value $<0.05$ was considered significant.

\section{Results}

Demographic and clinical characteristics of unmarried and married respondents with epilepsy according to gender are presented in Table 1 . There were 37 (63.8\%) women among unmarried PWE and 20 (52.6\%) women among married PWE. There were no significant differences between the two genders subgroups in terms of age, religion, seizure frequency and epilepsy type.

Table 1

Demographic characteristics of the sample.

\begin{tabular}{lcc}
\hline Variable & $\begin{array}{l}\text { Unmarried PWE } \\
(n=58)\end{array}$ & $\begin{array}{l}\text { Married PWE } \\
(n=38)\end{array}$ \\
\hline $\begin{array}{l}\text { Gender (females) } \\
\text { Education }\end{array}$ & $37(63.79 \%)$ & $20(52.63 \%)$ \\
$\quad$ Under matriculate & $10(17.2 \%)$ & $11(28.9 \%)$ \\
$\quad$ Matriculate and above & $48(82.7 \%)$ & $27(71 \%)$ \\
Religion & $25(43.9 \%)$ & $14(36.8 \%)$ \\
$\quad$ Hindu & $31(54.4 \%)$ & $22(57.9 \%)$ \\
Sikh & $1(1.75 \%)$ & $1(2.6 \%)$ \\
$\quad$ Muslim & & \\
Current seizure frequency & $29(50 \%)$ & $21(55.3 \%)$ \\
$\quad$ Frequent & $17(29.3 \%)$ & $17(44.7 \%)$ \\
$\quad$ Infrequent & $9(15.5 \%)$ & $17(44.7 \%)$ \\
Epilepsy syndrome & $30(51.7 \%)$ & $12(31.5 \%)$ \\
$\quad$ Focal epilepsy & $2(3.4 \%)$ & $1(2.6 \%)$ \\
Idiopathic generalized epilepsy & $17(29.3 \%)$ & $8(21.05 \%)$ \\
$\quad$ Others & & \\
$\quad$ Unestablished & & \\
\hline
\end{tabular}

Table 2

Demographic characteristics of general public $(n=150)$

\begin{tabular}{lc}
\hline Variable & Number (\%) \\
\hline Gender & \\
Males & $96(64 \%)$ \\
Females & $54(36 \%)$ \\
Age (years) & \\
$18-39$ & $127(84.6 \%)$ \\
$>40$ & $22(14.6 \%)$ \\
Education & \\
Under matriculate & $21(14 \%)$ \\
Matriculate and above & $129(86 \%)$ \\
Religion & $74(49.3 \%)$ \\
Hindu & $66(44 \%)$ \\
Sikh & $5(3.3 \%)$ \\
Muslim &
\end{tabular}


Table 3

Selected responses from unmarried PWE according to gender.

\begin{tabular}{|c|c|c|c|}
\hline Questions & & & $p$ value \\
\hline Are you aware of the legal aspects relating to marriage in PWE? & Males (21) & Females (36) & 0.036 \\
\hline Yes & $6(29 \%)$ & $2(6 \%)$ & \\
\hline No/not sure & $15(71 \%)$ & $34(94 \%)$ & \\
\hline Do you foresee taking your epilepsy medications secretly after marriage as a problem? & Males (10) & Females (7) & 0.009 \\
\hline Yes & $1(10 \%)$ & $5(71 \%)$ & \\
\hline No/not sure & $9(90 \%)$ & $2(29 \%)$ & \\
\hline During marriage negotiations, will you disclose that you have epilepsy? & Males (21) & Females (35) & 0.1281 \\
\hline Yes & $7(33.33 \%)$ & $19(54.28 \%)$ & \\
\hline No/not sure & $14(66.6 \%)$ & $16(45.6 \%)$ & \\
\hline If the diagnosis of epilepsy is exposed after marriage, do you think you will be ill-treated? & Males (10) & Females (10) & 0.001 \\
\hline Yes & $1(10 \%)$ & $5(50 \%)$ & \\
\hline No/not sure & $8(80 \%)$ & $5(50 \%)$ & \\
\hline $\begin{array}{l}\text { Do you feel that if you reveal the fact that you suffer from epilepsy, your prospective partner } \\
\text { will not accept the marriage proposal? }\end{array}$ & Males (20) & Females (35) & 0.359 \\
\hline Yes & $4(19.04 \%)$ & $11(31.42 \%)$ & \\
\hline No/not sure & $16(80 \%)$ & $24(68.57 \%)$ & \\
\hline
\end{tabular}

\subsection{Responses from unmarried PWE}

Responses to selected items in the survey form for unmarried PWE are presented in Table 3. Majority $(49 ; 87 \%)$ considered arranged marriage as the best way forward for realizing their matrimonial plans. Twenty-six (45\%) respondents declared that they would consider disclosure to either their prospective partners or their family during matrimonial negotiations. Of these, the majority (23; 89\%), however, would consider disclosing epilepsy to their prospective partners, while only three (11\%) purported to disclose epilepsy to their prospective in-law family. However, while only three (12\%) unmarried respondents with epilepsy would consider disclosing epilepsy during initial marriage negotiations, 22 (88\%) intended disclosure at some point in time after having reached to terms in the marriage negotiations place but before the wedding. Twelve (21\%) respondents stated that they would not disclose having epilepsy to their prospective partners at any point in time before marriage. Of those who preferred not to disclose, eight (67\%) anticipated breakdown of the marital negotiations; three (25\%) considered epilepsy too trivial to be disclosed and a sole subject thought that the condition would be cured after marriage.

A greater proportion of unmarried men (29\%) than women (6\%) with epilepsy were aware about the legal provisions relating to epilepsy in matrimony ( $p 0.04)$. More women $(5 ; 72 \%)$ than men ( 1 ; $10 \%$ ) apprehended problems in adhering to their epilepsy medications regime after marriage owing to an omission of disclosure prior to marriage ( $p$ 0.009). Likewise, a greater proportion of women $(5 ; 50 \%)$ in comparison to men $(1 ; 10 \%)$ apprehended victimization in marriage on account of epilepsy ( $p$ 0.001). Responses to other items in the questionnaire were similar between the two genders.

\subsection{Responses from married PWE}

Significant findings are given in Table 4. Only nine (25\%) married respondents with epilepsy stated to have disclosed epilepsy to their partners before marriage. Of these, five (56\%) disclosed the condition to their partner alone and not to other members of the in-law families. More married men (14; 78\%) than women $(11 ; 55 \%)$ with epilepsy indicated that they experienced a satisfactory married life. Moreover, while none of the male respondents believed that disclosure of epilepsy affected their married life, seven $(41 \%)$ women felt that the disclosure had a negative impact on their married life ( $p$ 0.047).

\subsection{Responses from the general public}

There were 96 (64\%) men and 54 (36\%) women among the general public respondents. Demographic data of the general public is given in Table 2 . Of these, $44(29 \%)$ had contended with epilepsy in themselves or their family/friends and the remainder (97; 63\%) had no such exposure to epilepsy. Responses in the two subgroups divided according to exposure to epilepsy are given in Table 5. More lay people exposed to epilepsy felt that they had reasonable information and knowledge about epilepsy $(p<0.001)$. Likewise, more exposed (to epilepsy) lay people were aware about the legal provisions relating to marriage in $\operatorname{PWE}(p<0.001)$. On the

Table 4

Selected responses from married PWE according to gender.

\begin{tabular}{|c|c|c|c|}
\hline \multicolumn{3}{|l|}{ Questions } & \multirow{2}{*}{$\frac{p \text { value }}{0.047}$} \\
\hline Did the revelation adversely affect your married life? & Males (9) & Females (17) & \\
\hline Yes & $0(0 \%)$ & $7(41.2 \%)$ & \\
\hline No/not sure & $9(100 \%)$ & $10(58.8 \%)$ & \\
\hline Did you disclose the fact that you have epilepsy before your marriage? & Males (18) & Females (19) & 0.209 \\
\hline Yes & $6(33.3 \%)$ & $3(15.78 \%)$ & \\
\hline No/not sure & $12(66.6 \%)$ & $16(83.2 \%)$ & \\
\hline Do you think that having epilepsy affected your intimate married life? & Males (18) & Females (20) & 0.272 \\
\hline Yes & $5(27.7 \%)$ & $9(45 \%)$ & \\
\hline No/not sure & $13(72.2 \%)$ & $11(55 \%)$ & \\
\hline Did epilepsy affect your decision to have children? & Males (17) & Females (19) & 0.279 \\
\hline Yes & $2(11.76 \%)$ & $5(26.31 \%)$ & \\
\hline No/not sure & $15(88.23 \%)$ & $14(73.68 \%)$ & \\
\hline Can epilepsy be a legal ground for divorce? & Males (18) & Females (20) & 0.881 \\
\hline Yes & $3(16.66 \%)$ & $3(15 \%)$ & \\
\hline No/not sure & $15(83.3 \%)$ & $17(85 \%)$ & \\
\hline
\end{tabular}


Table 5

Responses from general public according to previous exposure to epilepsy.

\begin{tabular}{|c|c|c|c|}
\hline & Exposed 44 (29.3\%) & Not exposed 97 (62.6\%) & $p$ value \\
\hline Do you feel that you have reasonable information and knowledge about epilepsy? (yes) & $18(40.95)$ & $12(12.7 \%)$ & $<0.001$ \\
\hline Are you aware of the legal aspects relating to marriage in PWE? (yes) & $12(27.2 \%)$ & $3(3 \%)$ & $<0.001$ \\
\hline Can epilepsy be a legal ground for divorce? (yes) & $13(29.5 \%)$ & $29(30.8 \%)$ & 0.800 \\
\hline Do you feel that epilepsy can be cured by getting married? (yes) & $6(13.6 \%)$ & $2(2 \%)$ & \\
\hline In your opinion should PWE get married? (no) & $2(4.5 \%)$ & $38(40.4 \%)$ & $<0.001$ \\
\hline Can epilepsy be transmitted from generation to generation? (yes) & $10(22.7 \%)$ & $12(12.7 \%)$ & 0.269 \\
\hline Are PWE unable to bear children? (yes) & $9(20.4 \%)$ & $33(35 \%)$ & 0.008 \\
\hline Women with epilepsy have children but they might be malformed? (yes) & $7(15.9 \%)$ & $15(15.9 \%)$ & 0.741 \\
\hline PWE often have problem in their sexual life (yes) & $21(47.7 \%)$ & $30(31.9 \%)$ & 0.007 \\
\hline These impairments are due to epilepsy itself? (yes) & $11(25 \%)$ & $25(26.4 \%)$ & 0.356 \\
\hline These impairments are due to epilepsy medications? (yes) & $7(15.9 \%)$ & $12(12.7 \%)$ & 0.801 \\
\hline
\end{tabular}

contrary, more people who lacked a past experience of epilepsy believed that PWE should not get married $(p<0.001)$ and are unable to bear children $(p=0.008)$.

\section{Discussion}

Although preliminary and limited by the small sample, this survey is noteworthy for several reasons. Data on knowledge about and attitudes towards marriage in PWE can be extracted from several generic KAP surveys; however, these cover a wide range of topics and hence provide only limited information about attitudes towards matrimony in PWE. ${ }^{5,8,9}$ To the best of our knowledge, there are no specific KAP surveys addressing matrimony in PWE. Moreover, the survey was undertaken in a community where arranged marriage is the social norm. Of note, arranged marriages are declining in most parts of the world. However, the majority of marriages in South Asian countries, e.g., 76\% in Nepal, ${ }^{14} 82-89 \%$ in India $^{12,15}$ and $88 \%$ in Pakistan ${ }^{16}$ are arranged.

We hypothesized that a number of variables might be associated with the state of knowledge and attitudes towards matrimony in PWE only in the closing of the survey. Hence, the decision to analyze the association between KAP responses and gender in PWE and exposure to epilepsy in the general public was post hoc. As a result, the comparison of responses between women and men with epilepsy was constrained by the small sample size. It is likely that given a larger sample, many more well-delineated differences in the responses of the two genders would have been forthcoming.

\subsection{Gender differences in attitudes towards matrimony in PWE}

More women in comparison to men with epilepsy were ignorant about the legal statutes relating to marriage in PWE. Whether a lower educational ranking of women was responsible for this difference could not be examined on account of a small sample size. Nearly one-half of unmarried women with epilepsy expressed forebodings of ill-treatment in marriage on account of epilepsy. This is probably an indication of the felt stigma associated with epilepsy. ${ }^{17}$ The felt stigma is responsible for concealing epilepsy at the time of marital negotiations. ${ }^{18}$ This pilot survey showed that $73 \%$ of the married women with epilepsy failed to disclose epilepsy to their spouses before marriage and 26\% of the unmarried PWE intended not to disclose epilepsy during marital negotiations. PWE apprehend breakdown of marital negotiations if they disclose epilepsy. Concealment of epilepsy is common worldwide during a variety of social situations. In an unrelated psychosocial experiment, lay subjects fared worse on health scales when they imagined expressing a personal secret to knownjudgmental listeners in comparison to unknown listeners and known-accepting listeners. ${ }^{19}$ The decision to conceal or not in any social interaction is influenced by the balance between the anticipated social consequences of disclosure and the perceived chances of detection (e.g., by the social contact witnessing a seizure).$^{20}$ Disclosing epilepsy during marital negotiations frequently leads to breakdown of the negotiations, considered despicable and humiliating by many. On the other hand, the chances of detection in those with controlled epilepsy are very small. Hence, PWE prefer to hide epilepsy during negotiations in arranged marriages. ${ }^{18}$ Hiding epilepsy in matrimony might be uncommon in western cultures. Because the prospective bride and groom are in proximate contact for long periods of time before marriage, it permits disclosure of discrediting traits. ${ }^{21}$ On the other hand, there is limited or often no contact between the prospective bride and the groom before marriage in the arranged marriages. For instance, a survey in India revealed that two third of the respondents who went through arranged matrimony admitted meeting their partner for the first time on their wedding day. ${ }^{22}$ Perhaps the limited communication between the prospective partners before marriage is responsible for the failure to disclose epilepsy in arranged marriages.

Hiding epilepsy from prospective partners before marriage presents a challenge to PWE who wish to continue to take their epilepsy medications after marriage. These PWE might continue to take their epilepsy medicines in a clandestine manner but the surreptitious use of medicines potentially leads to poor adherence. $^{23}$ In the current survey, more unmarried women with epilepsy apprehended problems with the use of epilepsy medicines after marriage. This is perhaps a reflection of the gender bias operational in a patriarchal (a situation where women move in to extended families of their male partners after arranged marriage) marriage. How this gender-specific felt stigma translates in terms of marital prospects and outcome remains to be studied.

\subsection{Public awareness about epilepsy}

The general public survey depicts the state of knowledge about and attitudes towards the practicalities of matrimony in PWE in communities, in which arranged marriages are common. For instance, nearly a third of the general public respondents believed that PWE should not get married and likewise thought that epilepsy might be a ground for divorce. This is despite the fact that the Hindu Marriage Act, which lays down legal statutes for a major proportion of the population in India was formally amended in 1999 to exclude epilepsy as a justification for divorce and annulment of marriage.

The general public survey also revealed that the lack of past experience with epilepsy was associated with a number of misplaced beliefs about and attitudes towards epilepsy. These can be addressed by increasing awareness about epilepsy among the public and understand the need for community education programmes for epilepsy. 


\section{Conflicts of interest}

The authors have none to declare.

\section{Appendix A. Supplementary data}

Supplementary data associated with this article can be found, in the online version, at doi:10.1016/j.ijep.2016.05.001.

\section{References}

1. Thomas S, Nair A. Confronting the stigma of epilepsy. Ann Indian Acad Neurol. 2011;14:158

2. Jacoby A, Austin J. Social stigma for adults and children with epilepsy. Epilepsia. 2007;48:6-9.

3. Bandstra N, Camfield C, Camfield P. Stigma of epilepsy. Can J Neurol Sci. 2008;35: 436-440.

4. Morrell M. Stigma and epilepsy. Epilepsy Behav. 2002;3:21-25.

5. Riasi H, Rajabpour Sanati A, Ghaemi K. The stigma of epilepsy and its effects on marital status. SpringerPlus. 2014;3:762.

6. Fernandes P, Noronha A, Sander J, Li L. Stigma scale of epilepsy: the perception of epilepsy stigma in different cities in Brazil. Arq Neuro-Psiquiatr. 2008;66: 471-476.

7. de Boer H, Mula M, Sander J. The global burden and stigma of epilepsy. Epilepsy Behav. 2008;12:540-546.

8. Tsuji S. [Social aspects of epilepsy: marriage, pregnancy, driving, antiepileptic drug withdrawal and against social stigma]. Rinsho Shinkeigaku. Clin Neurol.2004;44: 865-867.

9. Aziz H, Akhtar S, Hasan K. Epilepsy in Pakistan: stigma and psychosocial problems. A population-based epidemiologic study. Epilepsia. 1997;38:1069-1073.
10. Nambi S. Marriage, mental health and the Indian legislation. Indian J Psychiatry. 2005;47:3

11. Hamamy H. Consanguineous marriages. J Community Genet. 2011;3:185-192.

12. Mehndiratta MM, Paul B, Mehndiratta P. Arranged marriage, consanguinity and epilepsy. Neurol Asia. 2007;12:15-17.

13. Singh G, Pauranik A, Menon B, et al. The dilemma of arranged marriages in people with epilepsy. An expert group appraisal. 'UCL grand challenges, small grants initiative - Arranged Marriage in People with Epilepsy in India', Dayannand Medical College and Hospital, Ludhiana, Punjab, India, 04/19/2015'.

14. Ghimire D, Axinn W. Marital processes, arranged marriage, and contraception to limit fertility. Demography. 2013;50:1663-1686.

15. Statisticbrain.com. Arranged/Forced Marriage Statistics/Statistic Brain. 2016.

16. Jabeen N, Malik S. Consanguinity and its sociodemographic differentials in Bhimber District, Azad Jammu and Kashmir, Pakistan. J Health Popul Nutr. 2014;32(2): 301-313.

17. Bautista R, Shapovalov D, Shoraka A. Factors associated with increased felt stigma among individuals with epilepsy. Seizure. 2015;30:106-112.

18. Santosh D, Kumar T, Sarma P, Radhakrishnan K. Women with onset of epilepsy prior to marriage: disclose or conceal? Epilepsia. 2007;48:1007-1010.

19. Kelly A, Rodriguez R. Publicly committing oneself to an identity. Basic Appl Soc Psychol. 2006;28:185-191.

20. Troster H. Disclose or conceal? Strategies of information management in persons with epilepsy. Epilepsia. 1997;38:1227-1237.

21. Committee on Improving the Health, Safety, and Well-Being of Young Adults, Board on Children, Youth, and Families, Institute of Medicine, eds. et al.In: Investing in the Health and Well-Being of Young Adults. Washington, DC: National Academies Press; 2015. 3, Relationships. Available from: http://www.ncbi.nlm.nih.gov/books/ NBK284783/

22. Banerji M, Martin SP, Desai S. Is Education Associated with a Transition Towards Autonomy in Partner Choice? A Case Study of India. Presented at the IUSSP Seminar on Changing Transitions to Marriage: Gender Implications for the Next Generation, New Delhi. 2008.

23. Gururaj G, Satishchandra P, Amudhan S. Epilepsy in India II: impact, burden, and need for a multisectoral public health response. Ann Indian Acad Neurol. 2015;369-381. 